\title{
Have-on-Mask and Maintain-Physical-Distance: Are they the Outcome of Lockdown-Laws in Corona-
} Virus Crisis Country-Wise?

\author{
Akim M. Rahman, Ph.D. \\ Dept of Economics, School of Business, Canadian University of Bangladesh, Dhaka, Bangladesh \\ akim_rahman@hotmail.com,rahman.19@osu.edu
}

\begin{abstract}
The COVID-19 pandemic is an infectious disease that was initially detected in December 2019 in Wuhan City, China. Since then, it has been spreading country-wise on mild to severe scales, where Bangladesh, like most countries, was not prepared to meet the challenges. Addressing the crisis, Bangladesh,

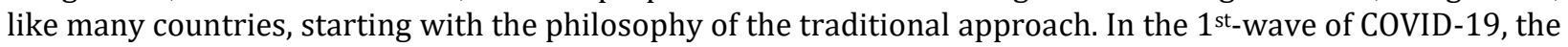
government implemented lockdown laws and enforced to have-on-mask and maintain-physical-distance. However, no government effort was seen ensuring modern-approach for convincing people, making people for their way understanding consequences \& preventive-measures thus people can take own decision facing perceived-risk. In the proposed approach, under Consumer Choice Theory, an individual's utility received from using face-mask and maintaining distance is equal to expected utility. Here outcome depends on an individual's efforts and the quality of the product individual uses. Any changes to these may risk getting infected, which may defeat the individual in fights with COVID-19. Rather than investing efforts only within main cities, the government could have reached out to rural areas by having local administration engaged. It could have weakened today's trends of catastrophes. The proposed approach could have been appealing to people for their actions in choices. It could ensure peoples' roles in society on moral-responsibility grounds. However, today's nation is witnessing the $2^{\text {nd }}$-wave and strict lockdown with provisions of arrest, penalties for violators. Since the number of death and infected people daily remained almost unchanged and since the mostly populated rural-area situation is not fully known, it is difficult to assess the effectiveness of government policies where the empirical study is warranted overcoming limitation. But people are now familiar with consequences and preventive measures in choices. This progression was not free-of-cost but with high-price-tag "so many lives", which could have been curtailed if modern strategies were in place.
\end{abstract}

Keyword(s): COVID-19 \& consequences, wearing mask \& often sanitation, traditional approach, modern approach, perceived risks, sense of responsibility, Consumer Choice Theory.

\section{Introduction}

The Corona virus Disease 2019 (COVID-19) is caused by a novel corona virus, which causes the severe acute respiratory problem. It was first detected in December 2019 in the city of Wuhan in Hubei province, China (Fauci, Lane \& Redfield, 2020). After the WHO declaration on public health emergency concerns in connection to COVID-19, over 40 countries have immediately declared extra health measures in multi-faucets. Several countries, that have denied entry to travelers or have put on hold the flights to and from China or other affected countries, are now reporting cases of COVID-19 (WHO, 2020). A cross-cutting economic activity, unlike any other, travel and tourism are confronted by the COVID-19 challenges. This is because of the essential people-to-people nature of the sector. In general, the spreading virus of epidemics is linked to public transportation for traveling, shopping mall, markets and tourism, etc. With these possibilities in human-dailylife activities, since the beginning of the crisis, the pandemic has been spreading country-wise with some cases slower and some cases at faster rates.

Addressing the issue globally, some governments country-wise have implemented traditional approaches such as policies or laws particularly lockdown, shutdown crowded spot(s) and forced to wear a mask and encourage for often sanitation. Bangladesh is no exception. Despite having Government's advice and lockdown-laws in place on maintaining physical distancing, regular hand-washing, wearing face mask and self-isolating if they have symptoms, a large population nationwide have ignored the advice and violated laws. The severity of this violation is comparatively low in city areas than that in the rural area where $65 \%$ of people reside (BBS, 2021). The government could have utilized approaches for convincing people, making them for understanding and then appeal to peoples' actions on a moral-obligation basis rather than using the traditional command \& control approach. Also, studies show that solving grand problems requires a sense of responsibility, coordinated efforts for pragmatic collaborations with stakeholders. 
Where understanding stakeholders" emotions, attitudes and preferences can be helpful (Doh, 2003; George et al., 2016; Muff, 2013) for an effective outcome. But it was missing in some country's efforts facing the corona crisis where Bangladesh is no exception. Since no country was prepared with knowledge for addressing the crisis, governments country-wise started their efforts on their traditional approaches even though today's human mentalities have been changed. And now accordingly, it asks for convincing, understanding \& appealing approaches over command \& control approach. Some countries have succeeded to manage their boundaries where they have done so based on their peoples' preferences - approaches of convincing, understanding, etc. However, in some other countries, despite traditional preventive measures in place, the consequences of COVID-19 have been spreading globally. In this process, some countries are going through the second stage of consequences. Bangladesh is now in its $2^{\text {nd }}$ wave. Rather than emphasizing humanappealing approaches of the modern world in designing preventive measures, the Bangladesh government has been sticking with its traditional approach, somewhat now stricter than it was in the $1^{\text {st }}$ - wave. In reality, the situation was getting worse in the $1^{\text {st }}$ wave, once the secrecy on practices of the Sabrina-ism (Rahman, 2021b), under the banner of the Directorate General of Health Services (DGHS) became known to the public (Rahman and Alif, 2020).

In public eyes, the DGHS was becoming a money-making machine in the early days of the crisis where the Ministry of Health (MoH) was the watchdog and Sabrina gong was seen as frontrunners of the money-sucking machine (Rahman, 2021b). Elaborating further on the reasons for the failure during the $1^{\text {st }}$-wave, it would not be overstated that some were doubtful about the extent to which the public would be willing and able to behave in the required ways. The other reasons might be certain individuals or groups of individuals, by their natures, oppose any legal \& moral standards in practice and react differently to the emerging phenomenon. For example, protecting others around the individual, the individual may feel it like "being mercy of those around". Because of lacking national protocol country-wise such as Bangladesh, when and where to wear a face mask, it is not quite unusual to be shamed for wearing one and angry when others don't. With these dilemmas in multi-phases, at the beginning of the crisis, the government of Bangladesh has made changes its positions many times on its strictness implementing policies underpinning command \& control theme. Accordingly, the government has confiscated the criminal activities - Forging Covid-19 Certificates, and has taken measures for its ending immediately. It has set up an example in the healthcare service arena in Bangladesh where the number of death was very low on a daily basis (Wasim and Adhikary, 2020).

In reality, the nation is now in its $2^{\text {nd }}$ wave on the severity of the consequences of COVID-19 where the nation's highest number of death was 258 in one day and a total of 14,925 people tested positive for the virus on that day (Star Digital Report, July 27 of 2021). Accordingly, the government has called on the Lawenforcement Agency (Police), Bangladesh Army, Border Guard of Bangladesh (BGB) and Rapid Action Battalion (RAB) for strict implementation of government laws on lockdown and to ensure wearing masks, maintaining physical-distance, etc. Since people are more familiar today with the severity of the crisis and people have learned the strictness of government roles \& policies and since the nation is in its $2^{\text {nd }}$ wave on COVID-19 severity, people are now more attentive to its actions than that during the $1{ }^{\text {st-wave. This }}$ progression raises the question: whether have-on-mask and maintain-physical-distance etc. are the outcomes of lockdown laws - traditional-approach? This study takes on the challenges of answering the questions posed using the Theory of Consumer Choices \& Behaviors. It continues with three specific objectives. They are:

- To identify factors that have undermined the effectiveness of government lockdown laws.

- To identify factors that have influenced wearing masks \& maintaining a physical distance.

- To examine how individuals feel in economics perspective wearing mask etc.

Why Bangladesh: The COVID-19 pandemic crisis is a global issue where Bangladesh is no out of the crisis. Like in many countries in the globe, Bangladesh has taken traditional-approach in multi-phases aiming to control Coronavirus transmission among people across the country. From the very early days, the government initiated its effort to control the transmission. On March 08, 2020, three patients were first identified to be COVID-19 infected where the number of death was zero (IEDCR, 2020) in Bangladesh. Figure- 2 shows that the Corona victim's death took place first on March 18 of 2020. On that day total of 3 people were identified as infected, shown in Figure 1. Initially, Bangladesh Government began its efforts with evacuations, travel restrictions, social distancing measures, shutting down schools, colleges, 
universities, etc. and finally imposing traditional approaches such as lockdown laws in Dhaka city and slowly beyond. Besides this, government-initiated testing and treatment of COVID-19 patients in govt. and in some private hospitals and clinics across the country. Since then the number of infected individuals was gradually increasing with the exception of March 29 of 2020 when no newly infected individual was identified but there were 3 deaths of corona patients in Figures $1 \& 2$. Since then the trends of the infected were increasing rapidly and trends of deaths were fluctuating slowly, which captured the pattern of wave 1 of COVID-19 consequences in Bangladesh.

\section{Fig 1: Confirmed Cases of Corona, Year 2020, $1^{\text {st }}$ Wave}

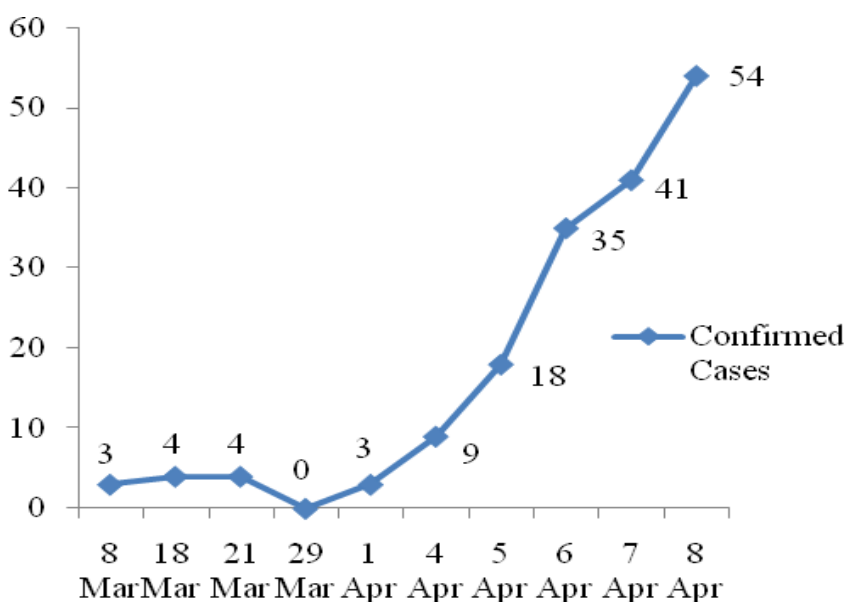

Data Source: IEDCR
Fig 2: Death in COVID-19, Year 2020, $1^{\text {st }}$ Wave

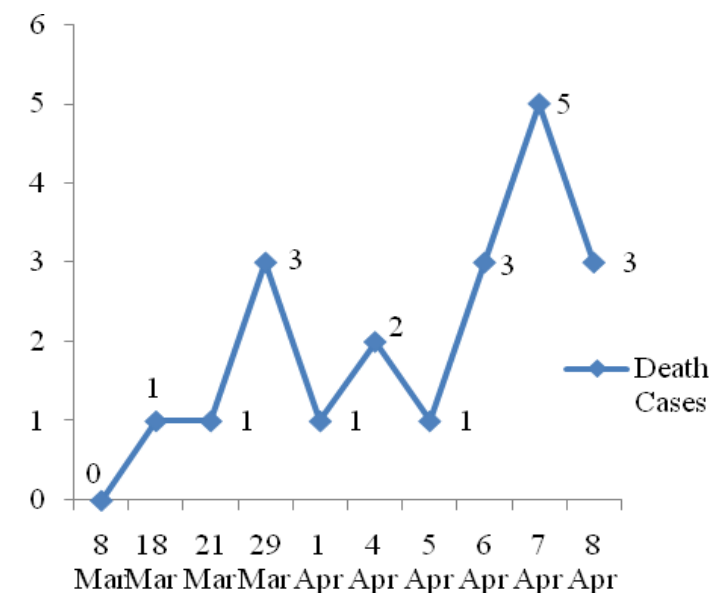

Data Source: IEDCR

However, Government's this journey began with the wrong signal to the public where the Directorate General of Health Services (DGHS) under the Ministry of Health was responsible for approving service providers conducting COVID-19 tests. JKG Healthcare was one of the approved service providers that were engaged in producing fake Covid-19 test reports and issued forged "Covid-19 Certificate". In reality, it got further ugly. The JKG was secretly led by physician Sabrina who was officially employed as Government Surgeon under the DGHS, MoH. With this reality, the general peoples' question "whether a higher number of people infected" was a creation of Sabrina-ism? This question is still active and it deserves to be investigated empirically. This Sabrina-ism of the DGHS under the umbrella of the MoH has polluted the entire healthcare service sector. In this process, many like Sabrina became the money-suckers at the frontline, DGHS was becoming a money-making machine and $\mathrm{MoH}$ was watching the Sabrina-ism where COVID-19 was a blessing for the parties involved with the costs of the public. Only the Sabrina group has been prosecuted but no change has yet been made to the leadership of the entity(s). Thus it is reasonable to claim "they are blessed" at least for now. This dilemma points to the nation's leadership one way or other. As a result, it has somewhat undermined the publics' sentiments on government law relates to lockdown, physical distancing, wearing masks, etc. in this pandemic crisis. In other words, people were coming back in normal lives and since the number of death per day was very low but growing, the government certainly pulled off the lockdown policies, media promotion for corona-test, etc.

All these dilemmas including the government's traditional approaches and then premature withdrawal lockdown in the $1^{\text {st }}$ wave of COVID-19 undermined it's much of the populations' psychological positive attitudes towards the seriousness of the Coronavirus in Bangladesh. This Sabrina-ism dilemma would not take place, if the government had started its journey with modern-approach relates to convincing people, making them understanding, etc. for inspiring people for moral-responsibility-ground behaviors rather sticking with command \& control traditional-approach. Rather than engaging in criminal activities, the Sabrina gong would have engaged with moral-responsibility-ground behaviors and extended official duties to their fullest where the government's modern approach would have inspired them. Also, during the $1^{\text {st }}$ wave, district-level healthcare services were not fully equipped \& ready for addressing the issues, which has undermined the effectiveness of the government's efforts. In the initial stage, the number of infected 
individuals was increasing slowly but the number of death was zero until March 17 of 2020, Figures 1 \& 2 . It has undermined much population's preferences to have on-mask and maintain physical distance. But because of economic necessities or unwillingness of the people to follow health rules such as lockdown laws, social distancing and have-on-mask, etc., the virus transmission has been increasing on an alarming scale in Bangladesh as reported (The Daily Star, June 28 of 2021). The current severity reflects that Bangladesh is now going through the $2^{\text {nd }}$ wave of Coronavirus transmission where the initial number of death was 5 to 10 in a day. Then it was becoming higher 30 to 40 in a day. Figure 1 \& Figure 2 show that the number of death reaches 212 in one day as of July $9^{\text {th }}$ and a total of 11,324 people tested positive for the virus on that day (The Daily Star, July 09 of 2021). Matter of fact, the death rate has been climbing fast.

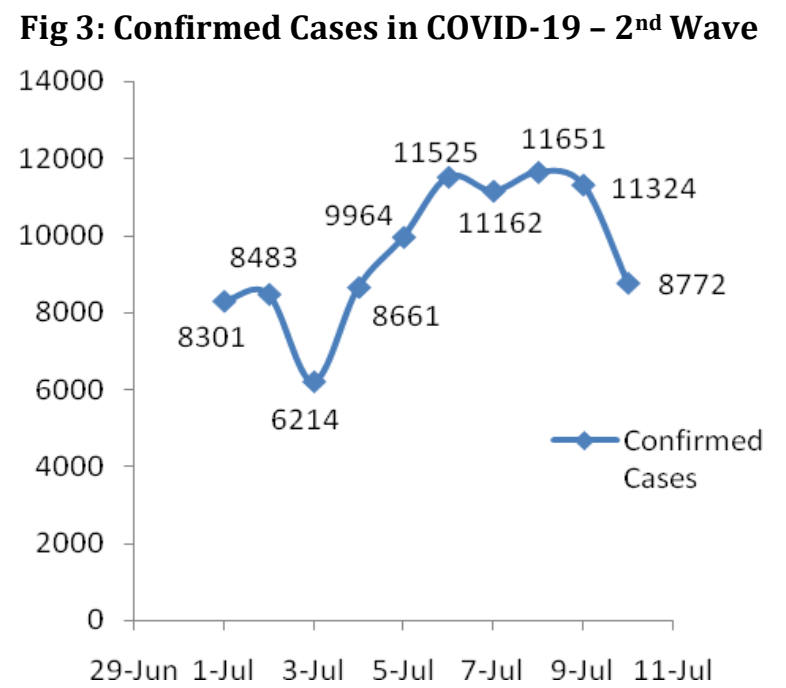

Data Source: Local Newspaper

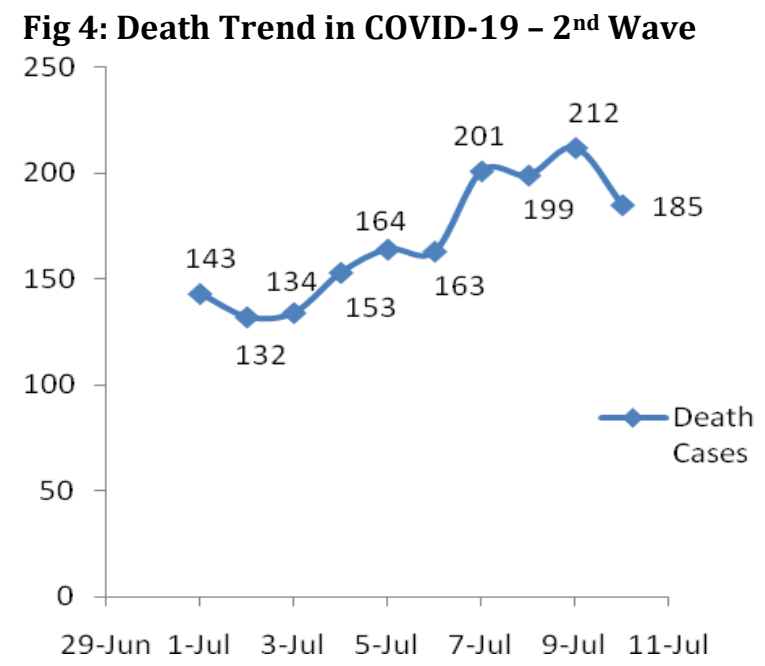

Data Source: Local Newspaper

The country continues to reel from the $2^{\text {nd }}$-wave of the pandemic as the trends of Covid-19 infected cases and deaths are rising on a daily basis. Figures $3 \& 4$ clearly show that June 29 of 2021 spiked the number of death and reached a total of 143 and since then the number has been growing with minor fluctuations on a daily basis. Similarly, the number of infected has been growing significantly. Facing this severity, the government imposed a shutdown nationwide for 7 days starting from July $1^{\text {st }}$ of 2021 where Police, the Army, BGB and $\mathrm{RAB}$ are called on to monitor strictly. Under this strict policy, just recently the government imposed a shutdown nationwide for 15 days, which lasted until August $10^{\text {th }}$ of 2021 . For any violations, people are faced with penalties including fines, get arrested, etc. Nowadays, these scenarios are frequently broadcasting on TV, radio, newspapers, etc. and what not. Besides this, media outlets now broadcast the specific death tolls district-wise on a daily basis. People now have more knowledge than before on the consequences of COVID-19 and the consequences of violation of lockdown law, mask-wearing violations. It is now forcing people to think deeply about their actions \& choices facing the perceived risk during the crisis.

Bangladesh is a southeast Asian middle-income country. Its economy has been flourishing rapidly and steadily for a while now. In the last decade, immense development was noticed in every sphere of life including women empowerment. Accordingly, the literacy rate of Bangladesh was 74.70 in the year 2020, which was 73.91\% in 2018 (BBS, 2020). Thus, in this modern Bangladesh, people here prefer more freedom and expect approaches like convincing, making understandable and appealing for making them do something in case of common goals. Also, people here, like any other people in the world country-wise, drive their life with hard work and mostly behave based on business-mentality - no mother feeds baby unless baby cries (Rahman, 2018). Thus, it is palatable believing that any effort whether it is from the government or private sector for a common goal, can be more effective with approaches other than the traditional command \& control approach. However, the incidence of the COVID-19 pandemic has influenced every sector of Bangladesh badly. Hence, the pandemic has become the worst threat to the life of the people of this country 
and its economy \& development. Hence this is the right time for Bangladesh to think of alternative initiatives to end this pandemic in Bangladesh otherwise it will have to pay a heavy price "so many precious lives".

\section{Elaboration of Concepts}

a. COVID 19 and its Consequences: The COVID-19 is a respiratory disease, which presents a range of illnesses from asymptomatic or mild through to severe disease and death. Since contact, droplets, etc. are the means of transmission, public health measures, such as hand hygiene and good respiratory etiquette (coughing into your elbow or a tissue and immediately disposing of the tissue), are vital to prevent infection. According to a report by the WHO (2020b), the speed of transmission for the COVID-19 virus is estimated to be 5-6 days. The reproductive number (the number of secondary infections from one infected individual) is said to be between 2 and 2.5. Children are less infected than adults, and clinical attack rates in the $0-19$ age group are low (WHO, 2020b).

b. The Sabrina-ism under the DGHS: Physician Sabrina Arif Chowdhury, who was employed as Government Surgeon in the National Heart Institute and Hospital under the DGHS, MoH, was directly involved in forging Covid-19 Certificates since the beginning of the COVID-19 crisis. Although she was working with the Government of Bangladesh, earlier she gave several interviews to the media as the Chairman of JKG Health Care (Liton, 2020). She was also employed as Chairman of JKG Health Care, the DGHS and the MoH like to call it "a secrete employment" (Liton, 2020). In law enforcement custody, Sabrina revealed that she had played important roles in obtaining permission from the DGHS for Covid-19 sample collection, but her partner misused the opportunity and issued fake Certificates without conducting tests (The Business Standard, July 17 of 2020). Apart from issuing fake Covid-19 Certificates, JKG has also made a good amount of money by providing telemedicine services, for which they were not permitted. In this episode, Sabrina was working as a money-sucker in the frontline and DGHS was becoming a money-making machine where the $\mathrm{MoH}$ was the watchdog under administrative setup. However, the leadership of the MoH, a political appointee, appointed by the current leadership of the nation was witnessing the entire Sabrina-ism in the healthcare-service arena.

Except for the Sabrina group, the leadership(s) of the relevant government entity(s) is appeared to be blessed for now. In the recent Parliamentary Budget Meetings, loud voices on the issue were raised before the political leadership(s) of the nation, but no response was produced. But the question is still active among the general people of this country. Despite the fact that the COVID-19 has caused more or less crisis worldwide, the COVID-19 was a blessing for the parties involved in the said episode in Bangladesh. This episode was called Sabrina-ism (Rahman, 2021b) named by physician Sabrina Arif Chowdhury who was directly involved in the forgery. This Sabrina-ism would not happen today if the government would have taken approaches based on peoples' preferences under the modern approach over the traditional approach. This is because, with the government's appealing approaches, the Sabrina gong could have followed their moral responsibilities and official obligations on duties. Thus, it can be educational and useful to authority(s) country-wise such as Bangladesh, if the leadership of a county requires initiating an investigation on probable misuses during Corona-crisis or beyond, for detecting departmental-wise public sector fraud.

c. Have-on-Mask and Maintain-Physical-Distance: Analysis of over 75,000 confirmed cases in China found no evidence of airborne transmission of COVID-19. Instead, the overwhelming evidence suggests that it is transmitted primarily through respiratory droplets and through contact. Coughing \& sneezes both are common COVID-19 symptoms. Thus, there has been an unprecedented global surge in the sales of medical face-masks. It has led to shortages of health workers in some parts of the world. With this limitation, many countries such as Bangladesh are making mask-wearing and maintain physical distance mandatory for anyone in public places. In some cases, these countries have imposed strict laws and made an arrest or monetary penalty. Other countries are now actively discouraging people from wearing them. As most agreed now that the COVID-19 virus is spread via much larger respiratory droplets between 5-10 micrometers in size (WHO, 2020b). These are too large to remain in the air for long and so instead it falls onto nearby surfaces. Anyone close enough can be infected if the droplets land on or around their mouth, nose and eyes or by touching a surface on which droplets have landed and then touching their faces. Thus wearing a mask and 
maintaining physical distance, one way or other, can be essential in aim to protect self from danger. Wearing a mask can also be helpful to others nearby where the individual has a moral responsibility in both ways. And for effective outcomes, it requires a sharpening sense of moral responsibility, coordinated efforts and pragmatic collaborations for getting it done. These are the ways the modern approaches have been progressing since the beginning of the $21^{\text {st }}$ Century era (Rahman, 2021a).

\section{Methodology}

In an aim to establish the basis of my theme - approaches other than the traditional approach, this study uses the Theory of Consumer Choice \& Behaviors (Rahman, 2019). It puts forward effective policy guidance for leadership country-wise such as Bangladesh as well as for an individual in deciding on its actions in aim to protect from COVID-19 and beyond. It is well recognized in human society country-wise that people prefer approaches that ensure freedom, convincing and profitable choices over any imposing approaches in case of a common goal. In today's society, human mentalities have been changed and now ask for convincing, understanding \& appealing approaches than command \& control - a traditional approach (Rahman, 2021a). Thus in this study, the following assumptions are made for individual's choices wearing a mask and maintaining a physical distance.

a) It is assumed that no relevant other factors, other than the severity of COVID-19 consequences, are changing.

b) Here a rational individual's preferences "have-on-mask" and "maintain-physical-distance" depend on the individual's understanding of the severity of the risk factor (consequences) and guidance on preventive measures.

c) These preferences are stable, total efforts (because of life \& death issue) and transitive for maximizing the utility of risk-protective choices such as have-on-mask and maintain-physical-distance, etc.

Have-on-Mask and Maintain-Physical-Distance under Consumer Choice Theory: It is now well recognized that the perceived-risk factor plays an influential role in an individual's decision (Rahman, 2018). It is no different using a mask etc. when a normal individual is around in public places during any pandemic crisis such as the COVID-19. It is palatable assuming that on a rationality perspective, an individual is riskaverse, i.e., the individual prefers certainty over uncertainty when it comes to saving himself from the danger out there. Figure 5 illustrates the risk preferences of a risk-averse for a rational and conscious individual who is concerned with himself. In a world-of-crisis such as COVID 19, an individual's actual benefit or utility that the individual receives using face-masks and maintaining physical distance, etc. will never fall on TU (X) but rather on the chord (the bold line) as shown in Figure 5. Point $X_{g}$, in Figure 5 represents outcomes of services $(\mathrm{X})$ from the mask, physical-distance, etc. in which the individual may use a certain level of X. Here servicequality $(S Q)=f$ (using products as directed, quality of the product and surely use them in public places). Quality of the product $(\mathrm{QP})=f$ (products) .

Here the outcome of the services depends on SQ and QP, which means getting not infected $=f$ (SQ and QP) where SQ and QP ensure their highest levels. Thus it costs higher for defeating the COVID-19. Any changes in SQ and QP may risk of getting infected with COVID-19. Thus it may cost lower, which may defeat the individual in fights with the COVID-19 crisis. In this setup, $\mathrm{X}_{\mathrm{g}}$ represents services derived from SQ and QP, which produces the highest outcome "not infected". Here $X_{\mathrm{f}}$ represents services derived from SQ and QP where $\mathrm{X}_{\mathrm{g}}>\mathrm{X}_{\mathrm{f}}$. In the case of $\mathrm{X}_{\mathrm{f}}$, an individual enjoys a lower cost for $\mathrm{QS}$ and $\mathrm{QP}$, which produces the outcome of "getting infected". As long as there exists a level of consequences of COVID 19, an individual may give a try to use $\mathrm{X}_{\mathrm{g}}$ units of service $\mathrm{X}$, the utility that this individual expects to receive will lie somewhere on the chord (the bold line). The chord represents the expected utility (EU) of using service $\mathrm{X}$, which lies in the concavity of the curve. This is because it is the average probability that the individual will use services $\mathrm{X}$ or not where $\mathrm{X}$ represents the combination of the SQ and QP. As a result, an individual will never receive TU $\left(X_{a}\right)$ but rather $\mathrm{EU}\left(\mathrm{X}_{\mathrm{a}}\right)$.

No Mask, No Service: Individual's Response on Moral-Responsibility Ground: Like in many countries, the Government of Bangladesh in the month of October 2020 introduced the policy that no one would be allowed to enter offices without a mask. And accordingly, all offices were asked to install notice boards saying 'no mask, no service' in order to control the spread of COVID-19 in Bangladesh (Star Digital Report, 2020). 
However, in reality, many places particularly haat-bazaar and religious places including prayer-places, etc, were, not monitored. It has been seen to be violated in multi-faucets. Rather than putting monitoring efforts into action, sometimes these places particularly prayer-places have been seen to be promoting "Almighty has given the pandemic for a test of humankind and accordingly He will resolve it". Despite these multi-phases behaviors of the people in Bangladesh, it is recognized that the government's policy "no mask, no service" is for inspiring the people here sharpening peoples' moral responsibilities in aim to address the pandemic crisis for survival.

This is because society is a system that organizes interactions between individuals and different groups with, at least a view for its survival through legal and moral standards in particular (Parsons, 1951). A particular standard-moral responsibility is a collection of rules allowing a system to organize itself optimally according to its goal. On the other hand, a legal standard is inscribed in law and a moral standard is not. On legal issues, punishment can be imposed based on Court decisions whereas, on morality issues, the leadership of a society can impose sanctions on individual misbehaves. Thus in this case "no service" can be seen as a sanction or punishment on an individual who does not follow social rules such as wearing a mask. Since the overall aim here is the survival of the society, like in many countries, the leadership of Bangladesh has introduced many policies such as "no mask no service" for addressing the phenomenon of COVID-19. Its absolute implementations could have brought better outcomes in meeting these ongoing challenges in Bangladesh where the nation is now going thru further strict lockdown law, which is scheduled for the next two weeks from July $23^{\text {rd }}, 2021$.

Fig 5: Corona Risk Aversion Scenario Using Face-Mask, Physical-Distance, etc.

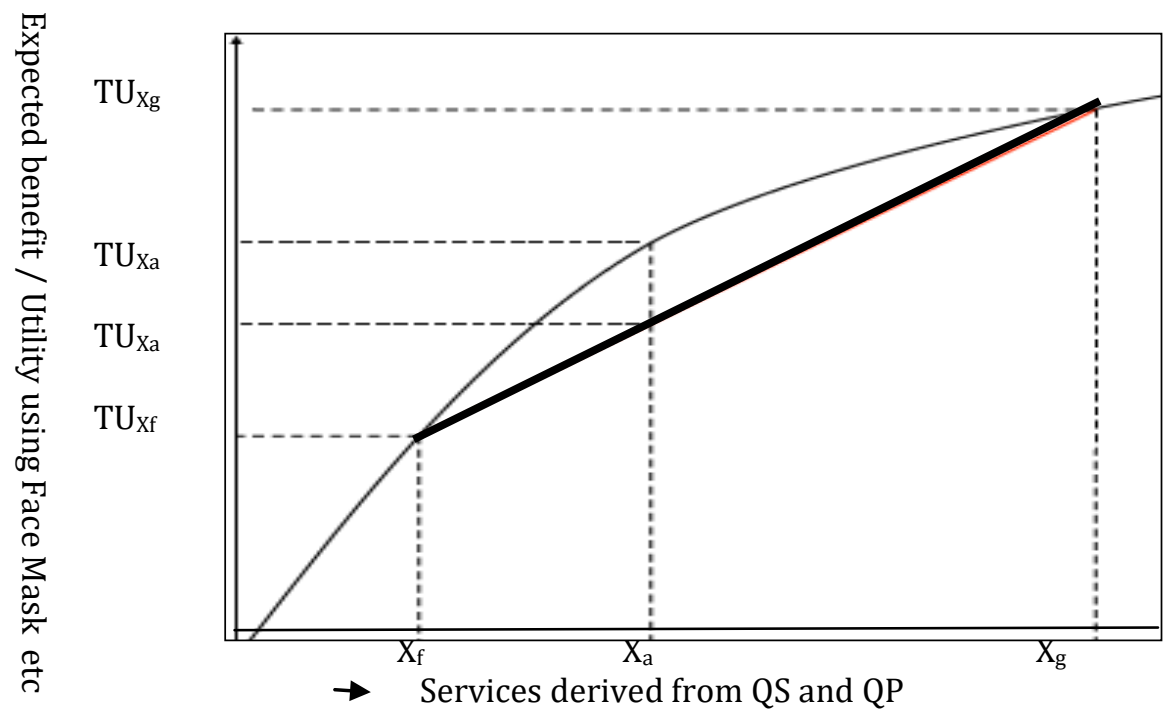

In this setup, individuals under the modern approach can receive more EU than individuals under the traditional approach. This is because, under the modern approach, individuals will have more information on consequences \& preventive measures and the resources available to them from multi-sources where the government will play significant roles. On the other hand, individuals under the traditional approach will have information on COVID consequences and preventive-measure mostly on their efforts, which sometimes become difficult unless individuals are well facilitated in lifestyles. It can be a significant issue for the people who reside in rural areas of Bangladesh. Under the traditional approach, individuals may have information on consequences \& preventive measures by struggling with lockdown laws. Thus EU received by an individual under modern-approach will be greater than the EU received by an individual under traditional-approach i.e. $\mathrm{EU}$ traditional-approach $<\mathrm{EU}$ modern-approach. An empirical study can approach questioning these findings.

Approaches Other than Lockdown-Laws - Traditional Approach: Policy Guidance: Since people in the globe country-wise as such Bangladesh have witnessed severe consequences even though they had opportunities leaning \& taking preventive measures in actions during the $1^{\text {st }}$ wave, policy-recommendations 
are designed based on experience from Bangladesh. Since the COVID-19 is an infectious virus (WHO, 2020), rather than individual's behavior, peoples' behaviors together could play significantly, if it was in effect in response to the pandemic in Bangladesh. In absence of vaccines, behavior by each individual of the public here was more crucial than that of the government's efforts alone meeting the crisis. Accordingly, this section advances analyzing and recommending probable approaches besides lockdown law, which can be instrumentally addressing any phenomenon like the COVID-19 or similar to it in Bangladesh and beyond. In general, the role of the group process (Drury, Carter, Ntontis and Guven, 2020) can be elaborated in this study in four categories addressing today's crisis of COVID-19. In each case, underpinning my accumulated research on behaviors in emergencies or disasters, I show that explanations to the public in terms of social identity processes can make better sense of the patterns of evidence than alternative explanations. The elaborations are as follows.

Recognition of the Threat as a Whole: Evidence suggests that most governments country-wise have acknowledged the corona-virus threat promptly (WHO, 2020). However, the authorities of some countries such as Bangladesh have done little to engage the people of Bangladesh, a three-tire country - rural, urban and cities, where $65 \%$ of people live in rural areas. Rather than traditional approaches, the local authority could promote the message on the danger of the COVID-19 using multi-media communication tools, if the local authority had, received an order from the central authority or leadership. Here probable communication tools are equipped with a microphone, short-video creation underpinning the theme of COVID-19 consequences and preventive measures, etc. Furthermore, the administration could have formed focusgroup(s), as they do political party-wise during the national election, block-wise thru local administration. So that these arrangements ensure that people block-wise in Bangladesh are familiar with COVID-19 consequences and have recognized the importance of preventive measures.

Guiding Public on Required Behaviors Facing the Crisis: In today's world, people are mostly driven by their own benefits in multi-faucets such as financial, feeling-good, self-recognition, self-pride, etc. (Rahman, 2021). In this decision-making process, an individual can be a risk-averse or risk-taker. Thus using technology facilitation, the proposed guidance should be in such a way so that groups or parties involved can be benefitted (Rahman, 2019) in aim to facing the crisis. Risk-benefit analyses can be useful in delivering messages for convincing individuals to take preventive measures for avoiding perceived risk. Most humans make decisions fairly subconsciously. So, by actually thinking about the risks and benefits of an individual's probable actions during this crisis, the individual can make better decisions on his or her choices.

Emphasizing Factors that Increase People's Fondness Facing the Crisis: In human society globally country-wise, it would not be overstated that using coercive measures such as threats, force, shouting, etc. can have backfire effects rather than enhancing effective public engagement on common issues such as the current crisis. However, when authorities manage the procedure and explain the importance to follow lockdown laws, have-on-mask, etc. and then authorities provide regular updates about authorities' actions, it increases perceptions of the legitimacy of the procedure among casualties.

Organizing for Actions of Community Mutual-Aid-Groups: Studies suggest that public involvement, in the form of active support for others-affected, is a necessary part of emergency response (Drury, Novelli and Scott, 2013) for effectively addressing any crisis. It is no different in today's COVID-19 crisis. Since coronavirus is an infectious disease (WHO, 2020), probably for that reason, the Bangladesh government has not yet officially inspired people for extending helps other than monetary to those who need it most. However, with government inspiration and facilitation of required equipment such as oxygen-cylinder, mask, etc. public would come forward, if the government had promoted so. Surely, every member of the public does not or may not provide support but many lives could have been saved by the 'average' citizen, whether 'bystander' or fellow survivor. Thus having the government's initiations for ensuring organized actions of the community could have ensured more people to make choices on supportive health behaviors, which could have ensured a lower number of people infected. It could have saved more lives than that are saved by professionals. Since the number of death and people-infected on a daily basis are not published area-wise such as Upazila, District or Division levels, even though it has been monitored as claimed, accordingly the government publishes only total numbers of death \& people-infected in Bangladesh. 


\section{Future Research}

It is palatable that human society country-wise is a combination of people of risk-averse and risk-takers. Thus this study imposes enough structure to allow meaningful welfare analysis where fewer assumptions at the cost of limiting the welfare analysis can be added. On empirical study, if research grants are available, multifaucets studies can be conducted on understanding peoples' behaviors when it comes to common goals meeting any challenges such as the COVID-19 crisis. Here multi-phases data collection using an opinion survey of healthcare service providers and general peoples' can be conducted. Factor analysis and hypothesis development \& testing can be carried out so that the expected findings can be educational meeting common goals such as any epidemic crisis in the future. It can also be instrumental in designing a school-level social science course curriculum to enhance readers' full understandings of their moral responsibilities to the society they live in.

\section{Conclusion and Recommendations}

The COVID-19 pandemic is an infectious disease that can cause a severe acute respiratory problem. It was initially detected in December 2019 in the city of Wuhan in Hubei Province, China. Since then, it has been spreading globally country-wise on a scale of mild to severe where most countries like Bangladesh were not prepared to meet the challenges. Addressing the crisis, like many other countries, the Bangladesh government started with the philosophy of traditional approach in the $1^{\text {st }}$ wave of COVID-19 and implemented policies particularly lockdown laws including legal forces wearing a mask and to maintain physical distance. However, no government effort was seen in practice that could ensure approaches for convincing people, making people for their way understanding the consequences \& preventive-measures, thus, people could decide on choices avoiding perceived risks. Here traditional approach was chosen over the modern approach addressing the crisis. In the proposed approach, under Consumer Choice Theory, an individual's actual utility that the individual receives using face-mask and maintaining physical distance is not equal to total utility but to the expected utility. This outcome depends on the individual's efforts and the quality of the product individual uses in choices. Thus, experience from Bangladesh suggests that any changes in an individual's own efforts can risk getting infected and defeated the individual in fights with COVID-19, which was mostly the outcome of the traditional approach over the modern approach.

Furthermore, the traditional approach has made the COVID-19 to be a blessing to many with the costs of the public in Bangladesh. Rather than putting efforts only within main cities, underpinning relevant leadership's foresees, by engaging local administration, the government could have reached out to residents in rural areas, which could have undermined today's trends of infected people and death. The proposed efforts could have been appealing to people for their actions in choices such as wearing-mask, maintain physical distance and ensuring peoples' roles in society on the moral-responsibility ground. It could enhance peoples' sense of responsibility, coordinated efforts and pragmatic collaborations with stakeholders today and in the future. However, today the nation is witnessing the $2^{\text {nd }}$-wave and strict lockdown laws with provisions of arrest, penalties, etc for violators. Since the number of death and infected people on a daily basis remain almost unchanged with minor fluctuation and since rural-area, where $65 \%$ of the population reside, the situation is not fully known, it is difficult to assess the effectiveness of the current strict policies in Bangladesh. But people now are familiar with consequences and preventive measures in their choices for ensuring to be on the safe side. This progression was not free-of-cost but with high-price-tag "so many precious lives", which could have been curtailed in numbers if modern strategies were in practice. However, empirical studies can approach questioning the findings.

\section{References}

Ahmed, M. (2021). Covid cases, deaths climb, The Daily Star, published March 23 ${ }^{\text {rd }}$ of 2021 https://www.thedailystar.net/frontpage/news/covid-19-cases-deaths-climb-2065077.

Bangladesh Bureau of Statistics (BBS). (2021). Bangladesh Literacy Rate 1981-2021, BBS https://www.macrotrends.net/countries/BGD/bangladesh/literacy-rate

Doh, J. (2003). Can leadership be taught? Perspectives from management educators, Academy of Management Learning \& Education, 2, 54-67. 
Drury, J. Carter, H., Ntontis, E. \& Guven, S. (2020). Public behavior in response to the COVID-19 pandemic: Understanding the role of group processes; Published online by Cambridge University Press, 07 December 2020

Drury, J., Novelli, D. \& Stott, C. (2013). Representing crowd behavior in emergency planning guidance: 'mass panic' or collective resilience? Resilience, 1(1), 18-37.

Fauci, A. S., Lane, C. H. \& Redfield, R. R. (2020). Covid-19-Navigating the Uncharted https://www.nejm.org/doi/full/10.1056/nejme2002387

George, G., Howard-Greenville, J., Joshi, A. \& Thayne, L. (2016). Understanding and tackling Societal, grand challenges through management research, Academy of Management Journal, 59(6), 1880-1895.

IEDCR. (2020). COVID - 19 Status for Bangladesh, Institute of Epidemiology, Disease Control and Research (IEDCR), March $18^{\text {th }}, 2020$ http://old.iedcr.gov.bd

Liton, S. (2020). Story of Shahed, Sabrina just the tip of the iceberg, The Business Standard, published July $13^{\text {th }}$ of 2020 https://www.tbsnews.net/analysis/story-shahed-sabrina-just-tip-iceberg-105601

Muff, K. (2013). Developing globally responsible leaders in business schools: A vision and transformational practice for the journey ahead. Journal of Management Development, 32(5), 487-507.

Parsons, T. (1951). The Social System, Printed Book, Published by Glencoe, Ill., Free Press.

Rahman, A. (2018). Voluntary Insurance for Ensuring Risk-free On-the-Go Banking Services in Market Competition: A Proposal for Bangladesh, The Journal of Asian Finance, Economics and Business, 5(1), 2288-4637, Boston University (USA), 5(1.29), 1-18.

Rahman, A. (2019). Microeconomics - Basics: New Way Learning Microeconomics in the 21 ${ }^{\text {st }}$ Century Era. ISBN: 978-0-9557163-0-0, Academic Textbook, Print Your Books Academic Publishing, Dhaka 1000, Bangladesh, 2019

Rahman, A. (2021a). $\mathrm{CO}_{2}$ Emission from Brickfields in Bangladesh: Can Ethical Responsibility by Doing Reduce Level of Emission, Athens Journal of Social Sciences, 8, 1-17. https://doi.org/10.30958/ajss.X-Y-Z.

Rahman, A. (2021b). Way to Demolish Sabrina-ism in Public Sector, The Daily Observer, Newspaper, published July 15 of 2021, https://www.observerbd.com/news.php?id=322010

Rahman, A. R. \& Alif, A. (2020), Police: Dr. Sabrina collected pay as JKGchairman, The Dhaka Tribune $\begin{array}{lllll}\text { Newspaper, } & \text { published } & \text { on } & \text { July } & \text { of }\end{array}$ https://www.dhakatribune.com/bangladesh/2020/07/16/db-dr-sabrina-collects-pay-as- $\quad$ jkgchairman.

Star Digital Report. (2021). Record 258 Covid-19 deaths, 14,925 new cases in 24 hours, The Daily Star $\begin{array}{lllll}\text { Newspaper, } & \text { published } & 7^{\text {th }} & \text { of } & 2021\end{array}$ https://www.thedailystar.net/health/disease/coronavirus/events-who infections/news/record258-covid-19-deaths-14925-new-cases-24-hours-2138266.

Star Digital Report. (2020). No mask, no service: Government decides, The Daily Star Newspaper, published October $25^{\text {th }}$ of 2020. https://www.thedailystar.net/country/news/no-mask-no-service-govtdecides-1984077

The Daily Star. (2021a). COVID rising in the heartland - Country logs highest positivity rate; deaths cross 19,000, The Daily Star Newspaper, Staff Report, published July 9th of 2021 https://www.thedailystar.net/health/disease/coronavirus/news/covid-rising-the-heartland2136171

The Daily Star. (2021b). Government to enforce stay at home, The Daily Star Newspaper, published June $28^{\text {th }}$ of 2021 https://www.thedailystar.net/bangladesh/news/govt-enforce-stay-home-2120021

Wasim, H. B. \& Adhikary, T. S. (2020). Fake COVID Certificates: Public health, country's image abroad at stake, The Daily Star Newspaper, Published July $9^{\text {th }}$ of 2020. https://www.thedailystar.net/frontpage/news/fake-covid-certificates-public-health- countrysimage-abroad-stake-1927393, e-Daily Star Newspaper

World Health Organization. (2020). WHO Director-General's opening remarks at the media briefing on COVID-19 - 11 March 2020 https://www.who.int/director-general/speeches/detail/who-directorgeneral-s-opening-remarks-at-the-media-briefing-on-covid-19---11-march-2020. 